\title{
Viral Oncogenesis in Tumors of the Central Nervous System: Reality or Random Association? A Retrospective Study on Archived Material
}

\section{Dorel Eugen Arsene}

Institutul National Victor Babes

Elena Milanesi ( $\nabla$ elena.k.milanesi@gmail.com )

Institutul National Victor Babes

\section{Maria Dobre \\ Institutul National Victor Babes}

\section{Research Article}

Keywords: glioma, meningioma, HPV, polyomavirus, herpesvirus, oncogenesis

Posted Date: February 1st, 2021

DOI: https://doi.org/10.21203/rs.3.rs-154755/v1

License: (c) (i) This work is licensed under a Creative Commons Attribution 4.0 International License.

Read Full License 
1 Viral oncogenesis in tumors of the central nervous system: reality or random association? A retrospective

2

3

4

5

6 7

8

9

\section{study on archived material}

\section{Dorel Eugen Arsene ${ }^{1,2}$, Elena Milanesi ${ }^{* 1}$ and Maria Dobre ${ }^{1}$}

${ }^{1}$ Victor Babes National Institute of Pathology, 050096 Bucharest, Romania;

${ }^{2}$ National Institute of Neurology and Neurovascular Diseases, 041914 Bucharest, Romania;

* Corresponding author: elena.k.milanesi@gmail.com

\section{Abstract}

Background: Central nervous system (CNS) tumors have devastating effects. They are recurrent, with dismal prognosis (gliomas) or life-threatening by compression effect (meningiomas). The etiology is still debatable, and over the last decade the hypothesis that human viruses may be implicated in these tumors has been proposed. Our aim was to examine the presence of eleven viruses in the most frequent CNS primary tumors. Methods: We assessed by PCR the viral presence in archived, paraffin embedded tumor tissues from 114 patients with glioma and meningioma and in the brain tissue from 40 controls lacking tumor pathology. We focused on candidate neuro-oncogenic types (herpesviridae and polyomaviruses) and on human papillomavirus (HPV). Results: HPV presence, for which an involvement in these tumors was hardly investigated, was found to be associated with both tumor categories compared with controls (glioma, $\mathrm{p}=0.032$; meningioma, $\mathrm{p}=0.032$ ), whereas the presence of the neuro-oncogenic viruses was found in a negligible number of both categories, suggesting a lack of association with the tumor presence. Moreover, our study revealed a positive correlation between HPV presence and glioma malignancy, and a negative correlation with meningioma grading. Conclusions: Our results suggest that the presence of HPV seems to be significantly associated with primary tumors of the CNS and its coverings.

Keywords: glioma; meningioma; HPV, polyomavirus, herpesvirus, oncogenesis 
Central nervous system (CNS) tumors account for a relatively small percentage of human tumors. However, since they cause morbidity and mortality that is disproportionate to their incidence, the mechanisms underpinning their etiopathogenesis are an important topic of research. There are over 100 different histological types of primary CNS tumors, with an annual age-adjusted incidence of 28.57 cases per 100.000 inhabitants. [1] The most common tumors affecting the brain are brain metastases, whereas among primary tumors, gliomas (comprising glioblastomas, astrocytomas, oligodendrogliomas and ependymomas) are the most prevalent malignant types, while meningiomas are the most common mostly histologically benign tumors affecting the CNS. Glioblastomas constitute $45 \%$ of malignant primary brain tumors and, according to the Central Brain Tumor Registry of the United States data (2008-2012), and meningiomas account for $35 \%$ of all primary brain tumors [2].

The aggressiveness of glioblastomas is both histological and clinical, determined by their localization within a rigid space and adjacent to vital areas; as an example, patients with glioblastoma, the most aggressive glial primary tumor, have a 5 years survival rate of $5.1 \%$ and a median survival around 10 months [3]. Recent approaches for glioblastoma therapy address some pathogenic features and are based on immunological and genetic-mediated techniques in addition to classical surgery, radio and chemotherapies [4-6]. For meningiomas standard therapy consists of surgery with or without adjuvant radiation, depending on the tumor grade and the degree of resection [7].

As for any other tumor types, knowing the precise etiology and pathogenesis would be the essential step in order to treat, cure, or even prevent their onset. Little is known about the etiology of these brain proliferative conditions and currently the only established risk factors are represented by ionizing radiation and some rare genetic related syndromes [8]. Moreover, there is growing evidence and consensus for the association of certain viruses with brain tumors [9]. Even though some viruses have been recently proposed as a therapeutic method for aggressive glial tumors [10-13], the viral role as an etiological agent is not sufficiently understood. Altogether, approximately $12 \%$ of human cancers has been supposed to have a viral etiology [14]. Human viral oncogenesis has been suggested to be characterized by three main features: a) oncoviruses are necessary, but not sufficient for the development of cancer; b) virus-dependent cancers occur many years after acute infection and after persistent chronic infections and; c) the immune system can act both in the direction of immunosuppression and chronic inflammation. $[15,16]$. Viruses activate various intracellular metabolic pathways, with the progressive accumulation of cellular markers that constitute the malignant phenotype. This is achieved by the 
accumulation of somatic oncogenic alterations (oncogenic strokes), caused by spontaneous mutations or mutations induced by exposure to environmental carcinogens, in the context of a genetic background of the host and the selective pressure imposed by the tissue microenvironment [17]. The viral oncogenic activity is most recently considered as oncomodulatory [18]. Several types of viral infection have been suggested to be potentially associated with CNS tumors, especially glioblastomas. Herpesviridae is a large family of DNA viruses that comprises Herpes Simplex 1 and 2 (HHV1, HHV2), Varicella zoster virus (HHV-3), Epstein-Barr virus (EBV or HHV-4), Cytomegalovirus (CMV or HHV-5), Roseolovirus (HHV-6 and HHV7) and Kaposi's sarcomaassociated herpesvirus (KSHV or HHV-8). These neurotropic viruses in the CNS are responsible for the activation of glial cells that release pro-inflammatory mediators and increase oxidative stress which are associated with neurodegenerative diseases pathogenesis. Indeed, the presence of many of these viruses hase been related to Alzheimer disease [19], Parkinson [20] and epilepsy [21].

Regarding cancer, although EBV and KSHV, are officially recognized as carcinogens, also the other viruses from this family have been associated with different types of cancer, but their role in carcinogenesis remains unclear [22].

Emerging evidence demonstrated the presence of human CMV proteins and nucleic acids in brain tumors in both adults and children [23], detecting the virus presence particularly in patients with high-grade gliomas (Ranganathan et al. 2012; Goerig et al. 2017). However, data are contrasting and the need for research into the involvement of this virus in gliomas has recently been argued $[25,26]$ since the CMV presence seems to be limited only to glioblastoma and not present in other types of glial tumors. [27, 28] Moreover, the real presence of CMV in gliomas is questioned $[29,30]$ and single cell sequencing does not clearly highlight the presence of this virus [31]

Also the results regarding the role of Epstein-Barr virus (HHV-4) in glioma genesis are controversial [32]. Although its presence was detected with a higher frequency than other herpesviruses (HHV-5, HHV-6, HHV-8) in pilocytic astrocytoma, it was not considered as being responsible for tumorigenesis in those cases [33]. Also HHV-6 is potentially involved in glial oncogenesis. The ability of HHV-6 to integrate into a chromosomal region that is highly relevant to carcinogenesis and the ability of HHV-6 ORF-1 protein to bind to p53 and its detection of early and late antigens in adult primary and recurrent CNS tumors (more frequently in glial tumors) [34] make this virus a potential key actor in glioma cases [35]. However, further studies are considered as mandatory [36]. 
HHV-8 or Kaposi's sarcoma-associated herpesvirus is well known for its oncogenic role in a wide category of haematological malignancies. However, since it has also a strong neurotropism [37], it could modulate the proliferation of glioma stem cells [38].

Moreover, HHV-2, EBV and HHV-6 have been detected in high-grade glioma tissues, and HHV-1 and HHV-2 immunoreactivity was found in some cases, although these were not detected in their tumor tissue [39].

Human polyomaviruses represent a diverse group of human pathogens comprising John Cunnningham virus (JCV), BK virus and simian virus 40 (SV40) that generally cause asymptomatic infection in healthy individuals. JC and BK viruses are described as being associated mostly with cutaneous and mucosal tumors, as well as with bladder carcinoma [40]. These viruses have been involved in neural oncogenesis, mainly in glioblastoma [39]. In particular, glioblastoma with small cell neuronal-like component was mainly related to JCV [41]. However, the role of this virus in carcinogenesis of brain tumors is not completely understood [42, 43].

Regarding SV40, most studies on its presence were performed in the sera of glioma patients, without assessing its presence within the brain tissue [44]. Moreover, differences regarding the detection methods (viral DNA, mRNA, expression of viral oncoproteins) are considered as essential in affirming or denying SV40 involvement as an oncogenic agent [45]. Finally, a potential involvement of HPV in glioblastoma has been suggested [28] since this virus has been found to have a prognostic implications in glioblastomas [46].

\section{Methods}

In this retrospective study we aim to detect the presence of various potential oncogenic viruses in the most frequent tumors of the brain and its coverings (glioblastoma and meningioma) compared to patients lacking tumor pathology.

\subsection{Sample collection}

In this study we enrolled 154 individuals. Fifty-six patients have been diagnosed with meningioma, and 58 with glioma (44 glioblastoma, 9 grade two diffuse astrocytoma and 5 anaplastic astrocytoma). Forty patients represented the control group, deceased by various pathologies and lacking any brain tumor. All study specimens have been collected from the Neuropathology Department of the National Institute of Neurology and Neurovascular Diseases. The study was conducted according to the guidelines of the Declaration of Helsinki and was approved by the Ethics Committee of the National Institute of Pathology "Victor Babes" (Registration number 
11553 of 6th December 2017). All the patients or their relatives signed the written informed consent. Only patients

116 with primary tumors of the brain and meninges have been enrolled. We excluded metastases (with biology specific

117 to the tissue of origin), glandular (pineal, pituitary) or accessory tissue (eye) tumors.

118 Serial 5- $\mu \mathrm{m}$ sections from formalin-fixed, paraffin-embedded (FFPE) tissues were cut from each paraffin block.

119 The first section was stained with Hematoxylin-Eosin and a second histopathological diagnosis was established

120 by an expert pathologist, in order to confirm the initial classification of the cases. All tumors were classified and

121 graded according to the WHO classification of CNS tumors [47]. Samples with a little amount of tissue, presenting

122 large necrotic area or presenting artefacts (i.e. intraoperative electrical mark), detected by microscopic

123 examination, have been excluded.

124 The initial series comprised all primary tumor categories of the brain, including oligodendroglioma, ependymoma,

125 choroid plexus tumors, etc, with a total of 200 cases. However, since most of these other entities were represented

126 by a too small number of cases, we restricted our research only to the most common and aggressive brain tumor,

127 the grade IV glioblastoma.

128 The sociodemographic and clinical data of the selected cohorts are reported in Table 1.

129

130

131

132

133

134

135

136

137

138

139

140 
Table1: Sociodemographic and clinical data of controls and patients involved in the study.

\begin{tabular}{|c|c|c|c|c|c|}
\hline & \multirow[b]{2}{*}{$\begin{array}{l}\text { Controls } \\
\mathrm{C}(\mathrm{N}=40)\end{array}$} & \multirow[b]{2}{*}{$\begin{array}{c}\text { Meningioma } \\
M(\mathrm{~N}=56)\end{array}$} & \multicolumn{2}{|c|}{ Glioma $\mathrm{G}(\mathrm{N}=58)$} & \multirow[b]{2}{*}{ p-value } \\
\hline & & & $\begin{array}{c}\text { Glioblastoma } \\
\text { GB } \\
\text { Grade IV } \\
(\mathbf{N}=44)\end{array}$ & $\begin{array}{c}\text { Astrocytoma } \\
\text { A } \\
\text { Grade II and } \\
\text { III }(\mathbf{N}=14)\end{array}$ & \\
\hline $\operatorname{Sex} F(N, \%)$ & $19(47.5 \%)$ & $36(64.3 \%)$ & $15(34.1 \%)$ & $9(64.3 \%)$ & $\begin{array}{l}M \text { vs } C \mathrm{p}=0.101 ; \chi^{2}=2.687 \\
G \text { vs } C \mathrm{p}=0.548 ; \chi^{2}=0.360 \\
G B \text { vs } C \mathrm{p}=0.243 ; \chi^{2}=1.364 \\
\text { A vs } C \mathrm{p}=0.279 ; \chi^{2}=1.170\end{array}$ \\
\hline Age \pm SD & $65.55 \pm 15.63$ & $57.52 \pm 12.78$ & $58.27 \pm 10.87$ & $47.29 \pm 14.28$ & $\begin{array}{c}M \text { vs } C p=0.007 \\
G \text { vs } C p=0.001 \\
G B \text { vs } C p=0.017 \\
A \text { vs } C p<0.001\end{array}$ \\
\hline \multirow{10}{*}{$\begin{array}{l}\text { Localization } \\
(\mathbf{N})\end{array}$} & Cortex $=25$ & $\begin{array}{l}\text { Convexity=3 } \\
5\end{array}$ & Temporal $=16$ & Frontal $=6$ & \\
\hline & Striatum $=4$ & Basal $=21$ & Frontal $=11$ & Temporal $=4$ & \\
\hline & $\begin{array}{l}\text { Hippocampus= } \\
3\end{array}$ & & $\begin{array}{l}\text { Parieto- } \\
\text { occipital=5 }\end{array}$ & Cerebellum $=1$ & \\
\hline & $\begin{array}{l}\text { Mesencephalon } \\
=3\end{array}$ & & Parietal $=3$ & $\begin{array}{l}\text { Fronto- } \\
\text { bilateral=1 }\end{array}$ & \\
\hline & $\begin{array}{l}\text { Hippocampus= } \\
3\end{array}$ & & $\begin{array}{l}\text { Temporo- } \\
\text { parietal=3 }\end{array}$ & $\begin{array}{l}\text { Fronto- } \\
\text { temporal=1 }\end{array}$ & \\
\hline & Cerebellum $=2$ & & $\begin{array}{l}\text { Fronto- } \\
\text { temporal }=2\end{array}$ & $\begin{array}{l}\text { Temporal- } \\
\text { lateral } \\
\text { ventricle=1 }\end{array}$ & \\
\hline & $\begin{array}{l}\begin{array}{l}\text { Cingulate } \\
\text { gyrus }=1\end{array} \\
\end{array}$ & & Cerebellum $=1$ & & \\
\hline & Pons $=1$ & & Fronto-parietal $=1$ & & \\
\hline & White matter $=1$ & & $\begin{array}{l}\text { Temporal-lateral } \\
\text { ventricle }=1\end{array}$ & & \\
\hline & & & Third ventricle $=1$ & & \\
\hline \multirow{3}{*}{ Grading } & & $\begin{array}{l}\text { Grade I, } \\
\text { benign=38 }\end{array}$ & & & \\
\hline & & $\begin{array}{l}\text { Grade II, } \\
\text { atypical=15 }\end{array}$ & & $\begin{array}{l}\text { Grade II, } \\
\text { diffuse } \\
\text { astrocytoma=9 }\end{array}$ & \\
\hline & & $\begin{array}{l}\text { Grade III, } \\
\text { malignant=3 }\end{array}$ & & $\begin{array}{c}\text { Grade III, } \\
\text { anaplastic } \\
\text { astrocytoma=5 }\end{array}$ & \\
\hline
\end{tabular}

144 A number of 5-10 slides $(50 \mu \mathrm{m})$ were cut from each sample, according to the volume. Before the DNA isolation, 145 in order to remove the paraffin, sections were placed at room temperature in two baths of xylene and absolute ethanol. Genomic DNA from FFPE tissue sections was isolated using the QIAamp DNA FFPE Tissue Kit (Qiagen, Hilden, Germany) according to the manufacturer's protocols. The quantity and purity of DNA were determined using the NanoDrop 2000 (Thermo Scientific, DE, USA). 

detected using dedicated Genesig Advanced kits (Primerdesign Ltd., York House, School Lane, Chandler's Ford, United Kingdom) by qPCR, following the instructions of the manufacturer on the ABI7500 fast (Applied Biosystem, MA, USA). Each kit comprises a positive control that contains templates for the targets in the test, and endogenous control to confirm extraction of a valid biological template. The presence of HPV has been detected by PCR using consensus primers targeting L1 region, GP5+/GP6+ primer set [48] as described by Yoshida et al [49]. This generated a 140-bp-long fragment from the HPV L1 structural gene. The amplified DNA was subjected to electrophoresis on $2 \%$ agarose gel, and then visualized by ultraviolet illumination using ethidium bromide. PCR reactions that were negative after first round, were subjected to a further 30 rounds of PCR amplification using the same primers (auto nested PCR) For samples found HPV positive by auto-nested PCR, genotyping has been performed using the AMPLIQUALITY HPV-TYPE EXPRESS v3.0 (AB Analitica, Padua, Italy) that allows the identification of the presence of HPV as well as the detection of 40 HPV genotypes: HPV 6, 11, 16, 18, 26, 31, 33, 35, 39, 40, 42, 43, $44,45,51,52,53,54,55,56,58,59,61,62,64,66,67,68$ (68a e 68b), 69, 70, 71, 72, 73, 81, 82, 83, 84, 87, 89, 90. This kit is IVD (In Vitro Diagnostic) marked for the detection of HPV also in histological FFPE samples. With this method, we did not obtained PCR products after the first amplification. Thus, PCR reactions were subjected to a further 30 rounds of PCR amplification (auto nested PCR)

\subsection{Statistical analysis}

Statistical analysis was performed using the Statistical Package for Social Science (SPSS version 17.0). Continuous variable (Age) was tested with the t-test. For categorical variables, frequency with percentages was reported and assessed for the two groups by $\chi^{2}$ test if the number of patients in a subgroup was $\geq 5$, and when the number was less than 5 in any cell, the Fisher exact test was applied.

\section{Results}

A total of 154 individuals have been involved in the study, including 79 female $(51.3 \%)$ and 75 male $(48.7 \%)$. The mean age of the study population was 58.89 years $(\mathrm{SD} \pm 14.01)$ Three groups have been made according to the diagnosis of meningioma $(n=56)$, glioma $(n=58$, including 44 glioblastoma and 14 astrocytoma) and control $(n=40)$. The groups were homogenous for sex, but not for age, since the control group was older than the groups 
of patients $(\mathrm{p}<0.05)$. Regarding the grading, in the meningioma group most of the tumors were of grade I $(67.86 \%)$ followed by grade II (26.78\%) and only 5.36\% were of grade III. The glioma group comprised the $75.86 \%$ of glioblastoma, grade IV and the $24.14 \%$ of astrocytoma. Among these, $64.28 \%$ were diffuse astrocytoma (grade II) and $35.72 \%$ anaplastic astrocytoma (grade III).

The presence of HPV was detected in the $20.78 \%$ of 154 analyzed samples with 3 positive cases in the control group, 14 in the meningioma group and 15 in the glioma group (13 in the glioblastoma and 2 in the astrocytoma subgroup).

The HPV presence was more frequent in patients with glioma compared to the control group with a significance of $\mathrm{p}=0.032$ (Fig 1a) as well as in the glioblastoma subgroup compared with controls $(\mathrm{p}=0.012)$ (Fig 1b). No statistical difference was found comparing the astrocytoma group vs control. A statistical significance was observed also comparing meningioma vs control group ( $\mathrm{p}=0.032$ ) (Fig 2a). In the meningioma group the presence of HPV was more frequent in meningioma of grade I, benign (12 positive cases out of $38,31.6 \%$ ) than in grade II, atypical (2 positive cases out of $15,13.3 \%$ ) and grade III, malignant where no positive cases has been detected on the three cases (Fig 2b).

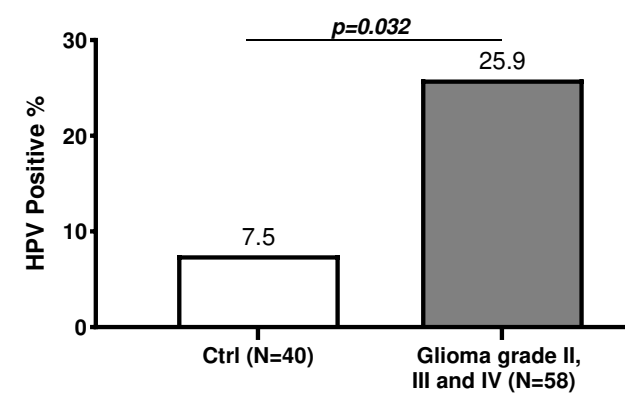

(a)

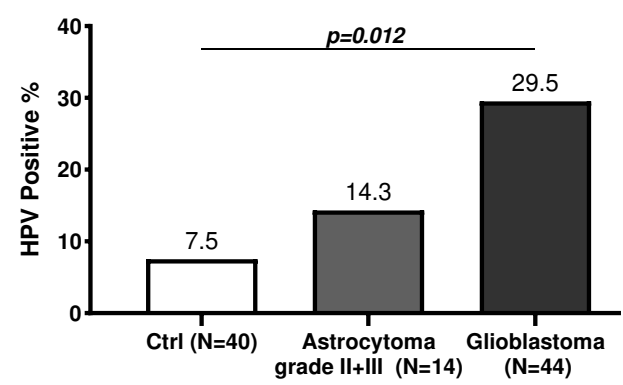

(b)

Figure 1: Percentage of positive HPV cases in control and glioma groups: a) comparison between controls and patients with glioma b) distribution of HPV positive cases in glioma groups stratified in astrocytoma and glioblastoma. 


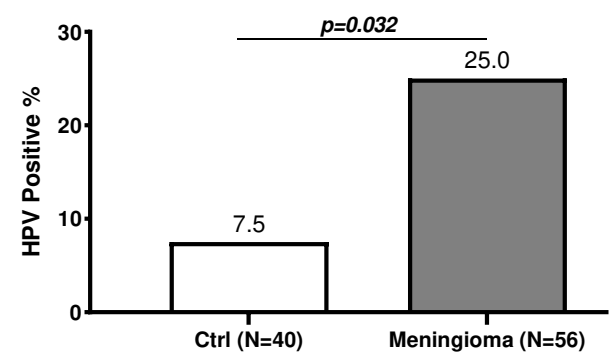

199

200

201

202

203

204

205

206

207

208

209

210

211

212

214 The distribution of HPV positive and negative cases in more stringent age categories is reported in (Additional 215 file 1: Table S2).

216

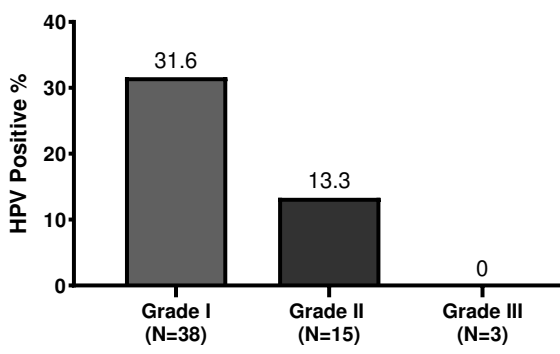

(b)
Figure 2: Percentage of positive HPV cases in control and meningioma groups: a) comparison between controls and patients with meningioma b) distribution of HPV positive cases in meningioma group stratified by grading

Regarding the localization no statistical difference has been observed between convexity meningioma (9 HPV positive cases out of 35) and basal meningioma (5 HPV positive cases out of 21). (Additional file 1: Table. S1)

The presence of HPV in the positive cases has been validated using an IVD kit. However, none of the 40 tested genotypes was found in our groups.

An analysis looking at the HPV frequency in age categories (Age $\leq 60$ and Age $>60$ ) has been conducted in the entire selected cohort and in the three groups. No statistical difference has been found between the two age categories in any analyzed group (Tab. 2).

Table 2: Distribution of HPV positive cases in age categories in the different analyzed groups

\begin{tabular}{|c|c|c|c|c|c|c|c|c|}
\cline { 2 - 9 } \multicolumn{1}{c|}{} & \multicolumn{2}{c|}{ All individuals (N=154) } & \multicolumn{2}{c|}{ Controls $(\mathbf{N}=\mathbf{4 0})$} & \multicolumn{2}{c|}{ Meningioma $(\mathbf{N}=56)$} & \multicolumn{2}{c|}{ Glioma (N=58) } \\
\cline { 2 - 9 } \multicolumn{1}{c|}{} & Age $\leq 60$ & Age $>60$ & Age $\leq 60$ & Age $>60$ & Age $\leq 60$ & Age $>60$ & Age $\leq 60$ & Age $>60$ \\
\hline HPV - & 62 & 60 & 16 & 21 & 21 & 21 & 25 & 18 \\
\hline HPV+ & 14 & 18 & 0 & 3 & 8 & 6 & 6 & 9 \\
\hline
\end{tabular}

The presence of HPV in sex categories was also investigated finding that in the entire cohort $(\mathrm{N}=154)$ the number of HPV positive cases was higher in the female group (26.6\%) than in the male group (14.7\%), however without 
218 statistical significance $\left(\chi^{2}=3.318, \mathrm{p}=0.069\right)$. This trend of difference between male and female was observed also

219 in the control, glioma and meningioma groups, again without statistical significance. (Additional file 1: Table S3)

220 HHV4-EBV was identified in $4.5 \%$ of total samples (3 positive cases in the control group, 1 in the meningioma 221 group, 1 in the glioblastoma subgroup and 2 in the astrocytoma subgroup). No statistical difference regarding the presence of this virus among the groups was found. One of the positive patients with glioblastoma has co-infection with HPV and another with HHV6.

224 HHV6 was detected in the same percentage as HHV4, but with a different distribution among the groups, with 4 positive cases in the control group, 1 in the meningioma group, 1 in the glioblastoma subgroup and 1 in the astrocytoma subgroup. Again, no statistical difference among the groups was shown. Of note, the patient with glioblastoma HHV6 positive presented co-infection with HPV.

228

The presence of HHV7 was detected only in one patient with meningioma with HPV co-infection, whereas the presence of HHV1-2, HHV5-CMV, HHV8, JCV, BKV, SV40 was not detected in the control group or in the patient group. All the results are shown in Table 3.

(1)

4

5

36

37


Table 3: Presence of all the analyzed viruses in controls, patients with meningioma and glioma

\begin{tabular}{|c|c|c|c|c|c|}
\hline & \multirow[b]{2}{*}{$\begin{array}{c}\text { Controls C } \\
(\mathrm{N}=\mathbf{4 0})\end{array}$} & \multirow[b]{2}{*}{$\begin{array}{c}\text { Meningioma } M \\
\quad(\mathrm{~N}=56)\end{array}$} & \multicolumn{2}{|c|}{ Glioma $G(N=58)$} & \multirow[b]{2}{*}{ p-value } \\
\hline & & & $\begin{array}{c}\text { Glioblastoma GB } \\
\qquad(\mathrm{N}=\mathbf{4 4})\end{array}$ & $\begin{array}{c}\text { Astrocytoma } \\
\text { A }(\mathrm{N}=14)\end{array}$ & \\
\hline HHV1-2 (N+, \%) & 0 & 0 & 0 & 0 & -- \\
\hline HHV4-EBV (N+, \%) & $3(7.5 \%)$ & $1(1.78 \%)$ & $1(2.3 \%)$ & $2(14.3 \%)$ & $\begin{array}{l}M \text { vs } C \mathrm{p}=0.305 \\
\mathrm{G} \text { vs } \mathrm{C}=0.686 \\
G B \text { vs } C \mathrm{p}=0.343 \\
A \text { vs } C \mathrm{p}=0.595\end{array}$ \\
\hline HHV5-CMV (N+, \%) & 0 & 0 & 0 & 0 & -- \\
\hline HHV6 (N+, \%) & $4(10 \%)$ & $1(1.78 \%)$ & $1(2.3 \%)$ & $1(7.1 \%)$ & $\begin{array}{l}M \text { vs } C \mathrm{p}=0.157 \\
\mathrm{G} \text { vs } \mathrm{C} \mathrm{p}=0.222 \\
G B \text { vs } C \mathrm{p}=0.187 \\
\text { A vs } C \mathrm{p}>0.999\end{array}$ \\
\hline HHV7 (N+, \%) & 0 & $1(1.78 \%)$ & 0 & 0 & -- \\
\hline HHV8 (N+, \%) & 0 & 0 & 0 & 0 & -- \\
\hline $\mathrm{JCV}(\mathrm{N}+, \%)$ & 0 & 0 & 0 & 0 & -- \\
\hline BKV $(\mathrm{N}+, \%)$ & 0 & 0 & 0 & 0 & -- \\
\hline SV40 $(\mathrm{N}+, \%)$ & 0 & 0 & 0 & 0 & -- \\
\hline HPV $(\mathrm{N}+, \%)$ & $3(7.5 \%)$ & $14(25 \%)$ & $13(29.5 \%)$ & $2(14.3 \%)$ & $\begin{array}{l}M \text { vs } C p=0.032 \\
G \text { vs } C p=0.032 \\
G B \text { vs } C p=0.012 \\
A \text { vs } C \mathrm{p}=0.595\end{array}$ \\
\hline
\end{tabular}

\section{Discussion}

247 In this study we explored the presence of infectious agents belonging to the Herpesviridae family (HHV -1, HHV2, HHV4-EBV, HHV5-CMV, HHV6, HHV7 and HHV8), polyomaviruses JCV, BKV and SV40 and HPV in patients with the most common brain tumors (glioma and meningioma) compared to a group of controls. We found that the most frequent virus in our analyzed cohort (40 controls, 56 meningiomas and 58 gliomas) was represented by HPV with $20.78 \%$ of positive cases. Specifically, HPV was detected in $25 \%$ of meningioma cases, $25.86 \%$ of glioma cases and in the $7.5 \%$ of control samples. Hence, HPV DNA presence was statistically more frequent in patients with glioma and meningioma compared to the controls ( $\mathrm{p}=0.032$ and $\mathrm{p}=0.032$, respectively). Of note, the HPV positivity in the glioma group was more present in the glioblastoma subgroup (29.5\%) compared to controls $(\mathrm{p}=0.012)$. 
A striking phenomenon is the negative correlation between the HPV positivity and meningioma grading, with the highest frequency of positive cases in grade I meningioma (31.6\%), followed by grade II (13.3\%) and no cases in grade III (malignant) tumors. This could be due to genetic abnormalities specific to each meningioma group (benign, atypical, malignant), which could interfere with the viral infection. Since the spectrum of histological types of meningeal tumors is remarkably wide, ranging from epithelioid cells, to obviously mesenchymal ones (as is the fibrous variant), such particular interactions between the cell of origin (the arachnoid cap cell) and HPV is supposed to generate mostly benign categories of meningothelial proliferations.

No statistical association between the other selected viruses and the analyzed brain tumors was observed in our study.

Our results on HPV in glioma and glioblastoma are in line with those reported by Vidone and collaborators [46] and by the research groups of Hashida [28] and Adnan [50] which found 25-28\% HPV positive cases in patients with glioblastoma, emphasizing the possible role of HPV in the pathophysiological mechanism of this tumor. Because of the positive correlation between HPV presence and glioma malignancy observed in our study $(14.3 \%$ in grade II and III astrocytoma and $29.5 \%$ in glioblastoma), we could speculate that HPV acts as a trigger for malignant transformation of normal glial cells: more cells infected generate a more intense proliferation index, increasing the tumor aggressiveness.

Again, in line with our findings, the Hashida study did not show a correlation between CMV as well as HHV -8 or EBV presence with glioblastoma [28]. In our study, the HPV DNA detection has been performed using two methods (in house PCR and a commercial IVD kit). None of the 40 HPV genotypes available in the kit was detected in our positive samples. This could mean that other HPV genotypes are involved in cerebral oncogenesis, or that the IVD kit, designed for detecting HPV in other tissues, such as mucosa or epidermis, are not adequate for processing brain tissue. In both procedures (in house PCR and IVD kit) the virus presence was detectable only after auto-nested PCR. This can be due to the low amounts of viral HPV DNA copies in brain tissues or to the tissue processing with large periods of formalin fixation. and brain tumors are in line with what found by Holdhoff and collaborators [27], although in others studies CMV, as well as other herpesviridae including EBV have been detected in glioblastoma and other gliomas [51, 52]. Of note, some of these studies have been performed without control cases, leading to a partial conclusion about the oncogenic role of these viruses in glioma and glioblastoma [53]. The lack of positivity for HHV-8 (even in the 

cases $(10 \%)$, compared to glioblastoma $(2.3 \%)$ or meningioma $(1.78 \%)$. This is in agreement with other studies which found a higher presence of this HHV type in lower grade gliomas [54].

Herpes viruses, mainly HHV-6, followed by HHV-1, HHV-3, EBV, HHV-2 and CMV, are present in relatively high percentages in the facial or trigeminal ganglia in the general population [55] and their role in oncogenesis has not been established. The peripheral presence of such infection does not mean that the infection propagate to the profound structures of the nervous system. The trajectory of the viral agent could be indeed stopped by the microenvironment conditions of the peripheral ganglia. This mechanism may represent an explanation of the low frequency of HHV positive cases detected in our entire cohort.

Finally, in our cohort the presence of polyomaviruses (JC, BK or SV40) was not detected. Data from literature affirm that in adulthood a large percentage of population have been infected with JC and BK viruses. Indeed, a sero prevalence of $39 \%$ for JC and $82 \%$ for BK was detected in other studies, with the profile of young subjects being similar to adults, demonstrating that the primary exposure occurs precociously in life [56]. However, these data derive from seric determinations and the presence of these polyomaviruses in the brain tissue was not determined in parallel. Hence, the viruses could be latent only in circulating mononuclear blood cells or the cells of the proximal renal tubule, reactivating in immunocompromised individuals.

\section{Conclusions}

Taken together our findings, even though based on a rather small amount of cases, show a significant increased frequency of HPV in glioblastoma and meningioma compared to normal brain tissue and suggest the noninvolvement of herpes and polyomaviruses in the investigated brain tumors. However, the detection of a virus within the tumor tissue is not sufficient to affirm its role as a causative agent. Further studies on larger cohorts are needed to clarify the role of these infectious agents in brain tumors in order to develop new preventive or therapeutic strategies.

List of abbreviations: BK, BK polyomavirus; CNS, central nervous system, CMV, cytomegalovirus; EBV, 

herpesvirus; SV40, Simian virus 40.

\section{Declarations}

316 Ethics approval and consent to participate: the study was conducted according to the guidelines of the

317 Declaration of Helsinki and approved by the Ethics Committee of the National Institute of Pathology "Victor 318 Babes" (Registration number 53 of 6th December 2017). All the individuals involved in the study or their relatives 319 signed the written informed consent.

Consent for publication: not applicable.

321 Availability of data and materials: All data generated or analyzed during this study are included in this

322 published article and its additional information files.

323 Competing interests: the authors declare that they have no competing interests.

324 Funding: this research was funded by the Ministry of Education and Research in Romania under grants no. PN 325 1N/2019_19.29.01.05 and by the European Regional Development Fund, Competitiveness Operational Program 2014-2020, through the grant P_37_732/2016 REDBRAIN.

327

Author Contributions: DEA coordinated the study, was responsible of the collection and diagnosis of the samples included in the study, revised the manuscript and gave the final approval of the version to be published. MD designed the study, performed virus detection, contributed to data processing and writing. EM was responsible for the statistical analysis and wrote the first draft of the manuscript. All authors have read and agreed to the published version of the manuscript.

Acknowledgements: Not applicable

\section{References}

1. Ostrom QT, Gittleman H, Fulop J, Liu M, Blanda R, Kromer C, et al. CBTRUS Statistical Report: Primary

Brain and Central Nervous System Tumors Diagnosed in the United States in 2008-2012. Neuro Oncol. 2015 ;17

Suppl 4:iv1-iv62. doi:10.1093/neuonc/nov189. 

doi:10.1016/j.amjmed.2017.12.039. Targets. Front Oncol. 2019;9:963. doi:10.3389/fonc.2019.00963. 4. Wheeler LA, Manzanera AG, Bell SD, Cavaliere R, McGregor JM, Grecula JC, et al. Phase II multicenter study of gene-mediated cytotoxic immunotherapy as adjuvant to surgical resection for newly diagnosed malignant glioma. Neuro Oncol. 2016;18:1137-45. doi:10.1093/neuonc/now002. mediated cytotoxic immunotherapy with AdV-tk as adjuvant to surgery and radiation for pediatric malignant glioma and recurrent ependymoma. Neuro Oncol. 2019;21:537-46. doi:10.1093/neuonc/noy202. immunosurveillance for children with high-risk malignant brain tumors. Neuro Oncol. 2019;21:419-20. doi:10.1093/neuonc/noz026.

7. Wang N, Osswald M. Meningiomas: Overview and New Directions in Therapy. Semin Neurol. 2018;38:11220. doi:10.1055/s-0038-1636502.

8. Perkins A, Liu G. Primary Brain Tumors in Adults: Diagnosis and Treatment. Am Fam Physician. 2016;93:211-7. http://www.ncbi.nlm.nih.gov/pubmed/26926614.

9. Cai Z, Yang S, Li X, Chen F, Li W. Viral infection and glioma: a meta-analysis of prognosis. BMC Cancer. 2020;20:549. doi:10.1186/s12885-020-06796-3. Virotherapy Promotes Intratumoral T Cell Infiltration and Improves Anti-PD-1 Immunotherapy. Cell. 2017;170:1109-1119.e10. doi:10.1016/j.cell.2017.08.027. Oncol. 2018;15:657-8. doi:10.1038/s41571-018-0077-0. 
13. Iorgulescu JB, Reardon DA, Chiocca EA, Wu CJ. Immunotherapy for glioblastoma: going viral. Nat Med. 2018;24:1094-6. doi:10.1038/s41591-018-0142-3.

14. Mesri EA, Feitelson MA, Munger K. Human viral oncogenesis: a cancer hallmarks analysis. Cell Host Microbe. 2014;15:266-82. doi:10.1016/j.chom.2014.02.011.

15. Bouvard V, Baan R, Straif K, Grosse Y, Secretan B, El Ghissassi F, et al. A review of human carcinogens-Part B: biological agents. Lancet Oncol. 2009;10:321-2. doi:10.1016/s1470-2045(09)70096-8.

16. zur Hausen H. The search for infectious causes of human cancers: where and why (Nobel lecture). Angew Chem Int Ed Engl. 2009;48:5798-808. doi:10.1002/anie.200901917.

17. Hanahan D, Weinberg RA. Hallmarks of cancer: the next generation. Cell. 2011;144:646-74. doi:10.1016/j.cell.2011.02.013.

18. Blaylock RL. Accelerated cancer aggressiveness by viral oncomodulation: New targets and newer natural treatments for cancer control and treatment. Surg Neurol Int. 2019;10:199.doi:10.25259/SNI_361_2019.

19. Sochocka M, Zwolińska K, Leszek J. The Infectious Etiology of Alzheimer's Disease. Curr Neuropharmacol. 2017;15:996-1009. doi:10.2174/1570159X15666170313122937.

20. Hemling N, Röyttä M, Rinne J, Pöllänen P, Broberg E, Tapio V, et al. Herpesviruses in brains in Alzheimer's and Parkinson's diseases. Ann Neurol. 2003;54:267-71. doi:10.1002/ana.10662.

21. Karatas H, Gurer G, Pinar A, Soylemezoglu F, Tezel GG, Hascelik G, et al. Investigation of HSV-1, HSV-2, CMV, HHV-6 and HHV-8 DNA by real-time PCR in surgical resection materials of epilepsy patients with mesial temporal lobe sclerosis. J Neurol Sci. 2008;264:151-6. doi:10.1016/j.jns.2007.08.010.

22. Alibek K, Baiken Y, Kakpenova A, Mussabekova A, Zhussupbekova S, Akan M, et al. Implication of human herpesviruses in oncogenesis through immune evasion and supression. Infect Agent Cancer. 2014;9:3. doi:10.1186/1750-9378-9-3.

23. Söderberg-Nauclér C, Johnsen JI. Cytomegalovirus infection in brain tumors: A potential new target for therapy? Oncoimmunology. 2012;1:739-40. doi:10.4161/onci.19441.

24. Goerig NL, Frey B, Überla K, Gaipl U, Fietkau R. A clinician's plea to test glioma patients for CMV. Neuro Oncol. 2017;19:1282-3. doi:10.1093/neuonc/nox080. 
25. Cobbs CS. Cytomegalovirus and brain tumor: epidemiology, biology and therapeutic aspects. Curr Opin Oncol. 2013;25:682-8. doi:10.1097/CCO.0000000000000005.

26. Johnson KJ, Hainfellner JA, Lau CC, Scheurer ME, Woehrer A, Wiemels J. Immune factors and viral interactions in brain cancer etiology and outcomes, The 2016 Brain Tumor Epidemiology Consortium Meeting report. Clin Neuropathol. 35:280-6. doi:10.5414/NP300985.

27. Holdhoff M, Guner G, Rodriguez FJ, Hicks JL, Zheng Q, Forman MS, et al. Absence of Cytomegalovirus in Glioblastoma and Other High-grade Gliomas by Real-time PCR, Immunohistochemistry, and In Situ Hybridization. Clin Cancer Res. 2017;23:3150-7. doi:10.1158/1078-0432.CCR-16-1490.

28. Hashida Y, Taniguchi A, Yawata T, Hosokawa S, Murakami M, Hiroi M, et al. Prevalence of human cytomegalovirus, polyomaviruses, and oncogenic viruses in glioblastoma among Japanese subjects. Infect Agent Cancer. 2015;10:3. doi:10.1186/1750-9378-10-3.

29. Wick W, Platten M. CMV infection and glioma, a highly controversial concept struggling in the clinical arena. Neuro Oncol. 2014;16:332-3. doi:10.1093/neuonc/nou002.

30. Rahman M, Dastmalchi F, Karachi A, Mitchell D. The role of CMV in glioblastoma and implications for immunotherapeutic strategies. Oncoimmunology. 2019;8:e1514921. doi:10.1080/2162402X.2018.1514921.

31. Johnson TS, Abrams ZB, Mo X, Zhang Y, Huang K. Lack of human cytomegalovirus expression in single cells from glioblastoma tumors and cell lines. J Neurovirol. 2017;23:671-8. doi:10.1007/s13365-017-0543-y.

32. Akhtar S, Vranic S, Cyprian FS, Al Moustafa A-E. Epstein-Barr Virus in Gliomas: Cause, Association, or Artifact? Front Oncol. 2018;8:123. doi:10.3389/fonc.2018.00123.

33. Neves AM, Thompson G, Carvalheira J, Trindade JC, Rueff J, Caetano JM, et al. Detection and quantitative analysis of human herpesvirus in pilocytic astrocytoma. Brain Res. 2008;1221:108-14. doi:10.1016/j.brainres.2008.05.009.

34. Crawford JR, Santi MR, Cornelison R, Sallinen S-L, Haapasalo H, MacDonald TJ. Detection of human herpesvirus-6 in adult central nervous system tumors: predominance of early and late viral antigens in glial tumors. J Neurooncol. 2009;95:49-60. doi:10.1007/s11060-009-9908-2.

35. Amirian ES, Scheurer ME. Chromosomally-integrated human herpesvirus 6 in familial glioma etiology. Med Hypotheses. 2012;79:193-6. doi:10.1016/j.mehy.2012.04.033. 

Malignancy: A Review. Front Oncol. 2018;8:512. doi:10.3389/fonc.2018.00512. in healthy brain. J Clin Microbiol. 2000;38:2772-3. doi:10.1128/JCM.38.7.2772-2773.2000. Infection Modulates the Proliferation of Glioma Stem-Like Cells. J Microbiol Biotechnol. 2018;28:165-74. doi:10.4014/jmb.1709.09001.

39. Strojnik T, Duh D, Lah TT. Prevalence of Neurotropic Viruses in Malignant Glioma and Their OncoModulatory Potential. In Vivo. 31:221-9. doi:10.21873/invivo.11049. 40. Mollerup S, Asplund M, Friis-Nielsen J, Kjartansdóttir KR, Fridholm H, Hansen TA, et al. HighThroughput Sequencing-Based Investigation of Viruses in Human Cancers by Multienrichment Approach. J Infect Dis. 2019;220:1312-24. doi:10.1093/infdis/jiz318. Glioblastoma multiforme with small cell neuronal-like component: association with human neurotropic JC virus. Acta Neuropathol. 2006;111:388-96. doi:10.1007/s00401-006-0050-3. and pathophysiology of glial tumours. Neurosurg Rev. 2016;39:47-53. doi:10.1007/s10143-015-0676-5. tumors. Infect Agent Cancer. 2017;12:10. doi:10.1186/s13027-017-0122-0. antibodies reacting with simian virus 40 mimotopes in sera from patients affected by glioblastoma multiforme. Neuro Oncol. 2014;16:513-9. doi:10.1093/neuonc/not217. Tumors. Front Oncol. 2019;9:670. doi:10.3389/fonc.2019.00670. doi:10.1093/neuonc/not140. 

Neuropathol. 2016;131:803-20. doi:10.1007/s00401-016-1545-1. human papillomavirus of the mucosa: comparison between MY09/11 and GP5+/6+ primer sets. J Clin Virol. 2004;30:302-8. doi:10.1016/j.jcv.2003.12.011. 49. Yoshida H, Murono S, Ueno T, Nakanishi Y, Tsuji A, Hatano M, et al. Usefulness of human papillomavirus detection in oral rinse as a biomarker of oropharyngeal cancer. Acta Otolaryngol. 2017;137:773-7. doi:10.1080/00016489.2016.1274426. Cytomegalovirus Infection and Association with Prognosis in Patients with Primary Glioblastoma in Pakistan. World Neurosurg. 2019;121:e931-9. doi:10.1016/j.wneu.2018.10.018. al. An overview of the infection of CMV, HSV 1/2 and EBV in Mexican patients with glioblastoma multiforme. Pathol Res Pract. 2017;213:271-6. doi:10.1016/j.prp.2016.12.006. virus DNA sequences in human gliomas. Sao Paulo Med J. 2015;133:51-4. doi:10.1590/15163180.2013.1912814. doi:10.1007/s11908-017-0563-z. herpesvirus-6 variants in pediatric brain tumors: association of viral antigen in low grade gliomas. J Clin Virol. 2009;46:37-42. doi:10.1016/j.jcv.2009.05.011. 55. Ptaszyńska-Sarosiek I, Dunaj J, Zajkowska A, Niemcunowicz-Janica A, Król M, Pancewicz S, et al. Postmortem detection of six human herpesviruses (HSV-1, HSV-2, VZV, EBV, CMV, HHV-6) in trigeminal and facial nerve ganglia by PCR. PeerJ. 2019;6:e6095. doi:10.7717/peerj.6095. 
$472 \quad$ 2009;5:e1000363. doi:10.1371/journal.ppat.1000363. 


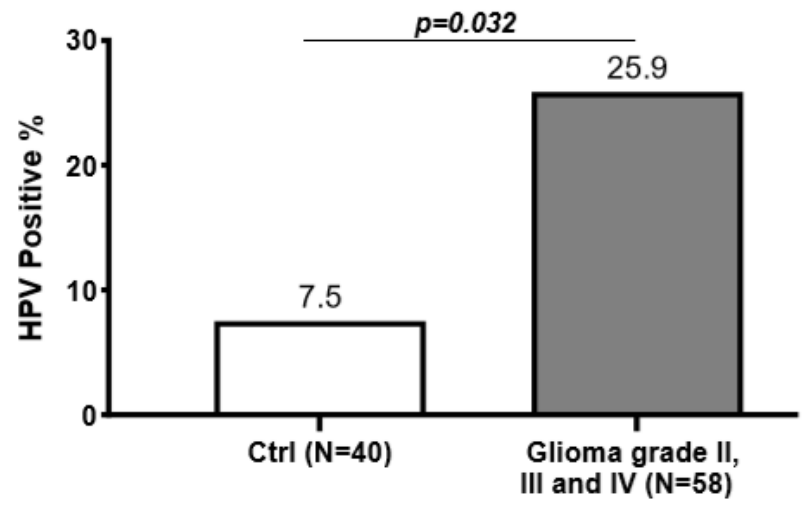

(a)

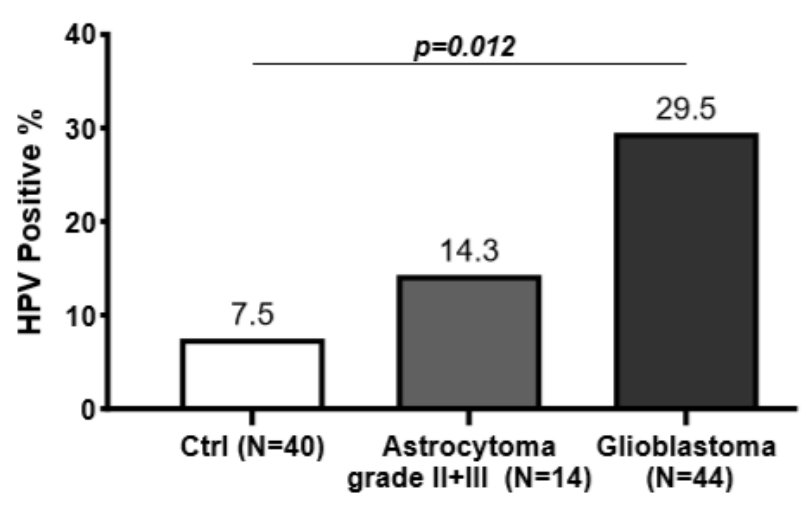

(b)

\section{Figure 1}

Percentage of positive HPV cases in control and glioma groups: a) comparison between controls and patients with glioma $b$ ) distribution of HPV positive cases in glioma groups stratified in astrocytoma and glioblastoma.

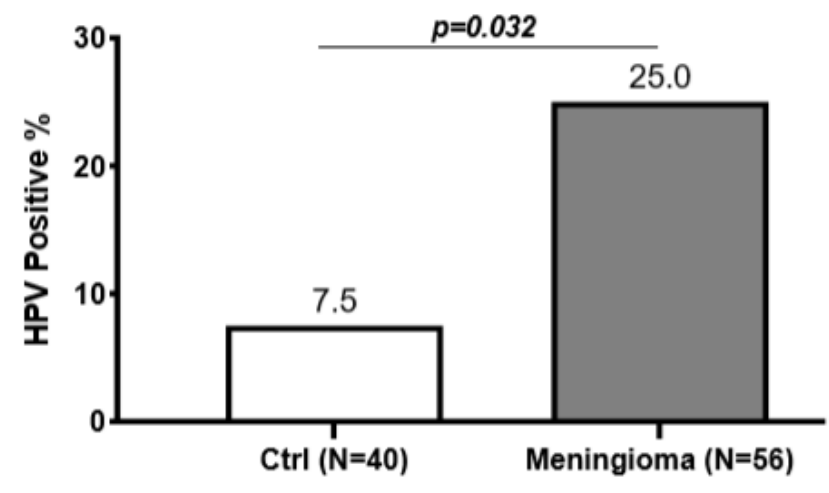

(a)

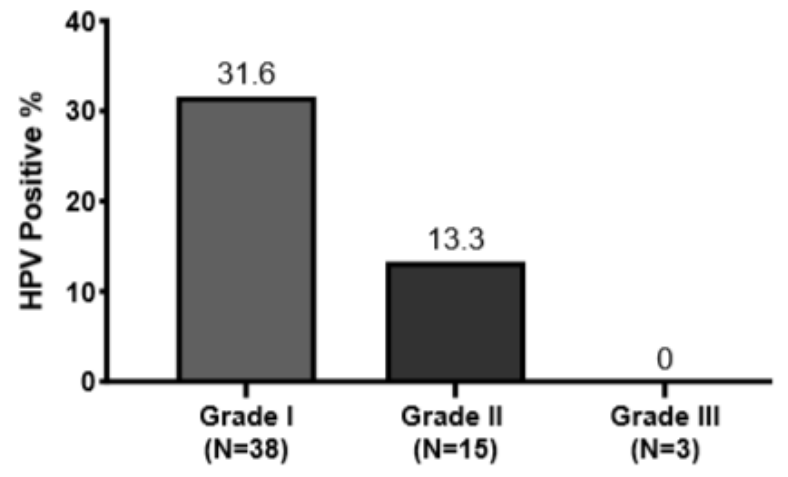

(b)

Figure 2

Percentage of positive HPV cases in control and meningioma groups: a) comparison between controls and patients with meningioma $b$ ) distribution of HPV positive cases in meningioma group stratified by grading 


\section{Supplementary Files}

This is a list of supplementary files associated with this preprint. Click to download.

- Additionalfile1Rev.pdf 